\title{
Language in the Senses: On Autistic Engagement with Words
}

\author{
Laura Sterponi \\ University of California, Berkeley, CA, USA
}

In this brief reflection, I invite rethinking autistic language from a phenomenological perspective, which attends to the experiential properties of verbal expression. I aim to argue that a treatment of language that goes beyond the denotational dimension of signification, integrating the symbolic with the nonreferential, allows for a more nuanced understanding of prototypical characteristics of autistic communication. I shall provide illustration with an excursus into autism echolalia.

Much of Western thinking about language, from Aristotle to Wittgenstein (the early Wittgenstein epitomized in his Tractatus Logico-Philosophicus (1922)), has viewed language as an autonomous denotational medium to represent reality - the actuality of phenomena in the outside world, as well as the somewhat more ephemeral domain of inner thoughts and feelings. Standing apart from the realm of reality, language is inherently outside of experience, and this language-experience distinction is what allows language to operate as a transparent means of representing the world. The essence of language, in this view, lies in its symbolic function, supplying (arbitrary) signs with which to refer to the outer world of nonlinguistic objects and the inner world of subjective experiences.

A phenomenological perspective invites recognizing that language and experience are in fact deeply intertwined, that language does not only represent experience but is an experience in and of itself. Such a perspective, as I have come to articulate it, draws from a range of theoretical contributions, from Jakobson's examination of the poetic function of language (Jakobson, 1960), to Kristeva's distinction between symbolic and semiotic dimensions of meaning (Kristeva, 1980), to a more recent analysis of language as a mode of experiencing the world, by linguistic anthropologist Elinor Ochs (2012).

Jakobson's analysis of poetic language acknowledges that language is not simply a conduit to something else but is perceived in itself (Jakobson, 1960). In poetic forms of language, the semiotic value of the sign vehicle in itself communicates. Rhyme, alliteration, other poetic devices - and especially parallelism, for Jakobson - realize the

\section{KARGER}

E-Mail karger@karger.com www.karger.com/hde (c) 2019 S. Karger AG, Basel 
reflexive and nonreferential potential of language, adding dimensions of signification to the denotational content.

Analysis of poetic language is also the springboard and foundation of Kristeva's theorization on language more broadly (Kristeva, 1980, 1984). In her monograph Revolution in Poetic Language (1984) most extensively, Kristeva articulates a distinction between the symbolic and the semiotic. These are two fundamental dimensions of meaning: the symbolic can be roughly described as encompassing the referential functioning of language - utterances with propositional content, signifiers standing for signifieds, language mobilized to predicate upon the world. The semiotic dimension, on the other hand, includes the nonreferential aspect of linguistic signification - notably tone, rhythm, prosody, the sound texture of words and phrases. The semiotic affirms language's materiality, its opacity, the purely sensorial dimension of language, what Kristeva refers to as "prelinguistic or translinguistic functioning of vocalism" (Kristeva \& Greenberg, 1978, p. 35), the possibility of linguistic expressions to be meaningful without denoting.

Albeit there is no direct scholarly lineage between the Russian formalism of Jakobson, the semiotic delineation of Kristeva, and Ochs' anthropological theorization, her 2012 essay "Experiencing Language" represents another incisive intervention towards a view of language that decenters the referential function. Contending that language at the symbolic level is incomplete, Ochs accentuates language's indexical and experiential properties. These properties bridge the divide between language and reality, situating language in intimate and coextensive relationship with experience. For Ochs, language is always constitutive of experience. Citing Agamben, she provides a simple but illustrative example. She invites considering any mundane object, any concrete noun, e.g. the word "shoe." Ochs observes that the word "shoe" is part of how we experience the objects to which this linguistic form conventionally refers. What it is like to produce and hear the acoustic contours of the word is a constitutive part of our experience of the object - much in the same way as its visible appearance and tactile contours. In this sense, the linguistic form is an attribute of the object and gives us access to some aspect of the object we are contemplating - its "shoeness." This example, in its simplicity and mundanity, suggests that language as an experience is not confined to poetic forms of expression but pertains to everyday uses: "Ordinary enactments of language [are] modes of experiencing the world" (Ochs, 2012, p. 149).

A view of language that includes phenomenological sensibility expands the horizon of interpretations of autistic engagement with words. More specifically, it problematizes the deficit perspective that characterizes prototypical features of autistic language as dysfunctional, notably echolalia. Where a deficit perspective sees (but we should say "hears") stultifying regurgitation of the words of self or others, a phenomenological view suggests the possibility of meaningful acts, motivated by attunement to sound and rhythm, and to the vocal tract's makeup of words and phrases. Autistic engagement with words seems unsubjugated to the referential regime, reveling in the acoustics of segments, the musicality of phrases, and their articulatory features, as they are experienced in the ear and in the mouth.

In addition, when autistic children repeat the words of others, I see an orientation towards trying on others' perspectives. This repetition is an act of revoicing that can support identification with the other, an experience of embodied, sensuous perspective taking. When we consider the experiential dimension of language, revoicing 
as linguistic resource makes possible an experience with the other, rather than solely an experience of the other. This perspective allows us to recognize that what appears to be an atypical self-directed use of language is in fact an effective medium for engagement with the world of others. Echolalia might be among the most ordinary enactments of language in autism. In this experiential mode we find autistic children relating, appropriating, transforming, and creating.

\section{References}

Jakobson, R. (1960). Closing statement: linguistics and poetics. In T. Sebeok (Ed.), Style in language (pp. 398-429). Cambridge, MA: The MIT Press.

Kristeva, J. (1980). Word, dialogue, and novel. In L. S. Roudiez (Ed.), Desire in language: A semiotic approach to literature and art (pp. 64-91). New York, NY: Columbia University Press.

Kristeva, J. (1984). Revolution in poetic language. New York, NY: Columbia University Press.

Kristeva, J., \& Greenberg, C. (1978). Phonetics, phonology and impulsional bases. Diacritics, 4(3), 33-37. https://doi.org/10.2307/465110

Ochs, E. (2012). Experiencing language. Anthropological Theory, 12(2), 142-160. https://doi. org/10.1177/1463499612454088

Wittgenstein, L. (1922). Tractatus logico-philosophicus. London, UK: Kegan Paul.

Language in the Senses: On Autistic Engagement with Words
Human Development 2019;63:87-89 DOI: $10.1159 / 000501689$ 